\title{
(t)
}

\section{O PROJETO PROFISSIONAL DO SERVIÇO SOCIAL EM DEBATE: ENTRE A INTENÇÃO DE RUPTURA E AS TENDÊNCIAS DO NEOCONSERVADORISMO}

The professional project of the Social Work in debate: between the intention of rupture and the tendencies of neoconservatism

\section{Joseane Barbosa de Lima'}

\section{RESUMO}

Este artigo tem como objeto de estudo o Projeto Ético Político do Serviço Social brasileiro e como objetivo analisar os desafios para a materialização do Projeto Ético Político do Serviço Social brasileiro na contemporaneidade, no contexto de avanços do neoconservadorismo. Para alcançar o objetivo proposto realizouse uma pesquisa bibliográfica ampla que permitiu a análise reflexiva objeto. Considera-se que o contexto capitalista contemporâneo, é extremamente propício ao avanço das expressões neoconservadoras na formação profissional dos Assistentes Sociais, comprometendo a materialização do Projeto Profissional formulado no fim dos anos 1980. Apesar do contexto adverso, afirma-se que o Serviço Social brasileiro permanece no campo da resistência teórico-política, na defesa uma novo projeto societário.

\section{PALAVRAS-CHAVE}

Serviço Social. Projeto Ético Político. Desafios.

\section{ABSTRACT}

This article has as object of study the Political Ethical Project of Brazilian Social Service and aims to analyze the challenges for the materialization of the Political Ethical Project of the Brazilian Social Service in contemporaneity, in the

\footnotetext{
${ }^{1}$ Assistente Social. Doutoranda em Serviço Social pela Universidade do Estado do Rio de Janeiro (UERJ, Rio de Janeiro, Brasil). Professora substituta na Escola de Serviço Social da Universidade Federal do Rio de Janeiro (UFRJ, Rio de Janeiro, Brasil). Av. Pasteur, 250 - Urca, Rio de Janeiro (RJ), CEP.: 22290-240. E-mail: $<$ jo.asocial@hotmail.com>.
} 
context of neoconservative advances. In order to reach the proposed objective, a broad bibliographical research was carried out, which allowed reflective object analysis. It is considered that the contemporary capitalist context is extremely conducive to the advancement of neoconservative expressions in the professional training of Social Workers, compromising the materialization of the Professional Project formulated in the late 1980s. Despite the adverse context, it is affirmed that the Brazilian Social Service Remains in the field of theoretical-political resistance, in defense a new corporate project.

\section{KEYWORDS}

Social Service. Political Ethics Project. Challenges.

Submetido em: 14/9/2016

Aceito em: 24/5/2017

\section{INTRODUÇÃO}

As reflexões desenvolvidas neste trabalho objetivam trazer uma reflexão acerca do projeto ético-político do Serviço Social construído na década de 1980, procurando problematizar suas conquistas, materialização, limites e desafios perante esse processo sócio-histórico de avanço destrutivo do capital.

Sabe-se que esse Projeto conquistou sua hegemonia na primeira metade da década de 1990, destacando-se principalmente pela sua produção de conhecimento, sob direção da teoria social crítica de Marx; pelos seus marcos normativos, cuja expressões são o Código de Ética profissional de 1993, a Lei de Regulamentação da Profissão 8662/93 e pelas Diretrizes Curriculares para os cursos de Serviço Social (1996) formuladas pela Associação Brasileira de Ensino e Pesquisa em Serviço Social (ABEPSS) num processo democrático e de ampla representatividade da categoria, apontando para as lutas contra o projeto do capital.

Assim, o presente trabalho apresenta inicialmente, uma análise sintética do processo de renovação crítica do Serviço Social brasileiro, enquanto herança do Movimento de Reconceituação latino-americano; a construção do Projeto ético-político profissional voltado fundamentalmente às preocupações da classe trabalhadora, e caminha num segundo momento, para reflexão das condições sócio-históricas que tensionam a sua integral implementação, abordando as concepções polêmicas e divergentes sobre a existência de uma suposta crise de hegemonia do Projeto Profissional na contemporaneidade. 


\section{O PROCESSO DE RENOVAÇÃO CRÍTICA DO SERVIÇO SOCIAL BRASILEIRO A PARTIR DA DÉCADA DE 1980}

O Serviço Social tem fundamentos e mediações cujas determinações são colocadas pelas demandas que se apresentam. Tradicionalmente a dimensão teórica e interventiva desta profissão foi orientada por pressupostos político-ideológico voltados para o fortalecimento de relações de dominação.

A gênese da profissão, conforme a análise de Netto (1992), data do contexto de expansão e acumulação do capitalismo monopolista, com estreitas relações com o projeto social da igreja católica que imprimiu à profissão uma dimensão política de caráter moralizador e acrítico. Neste, como mero executor de políticas sociais as ações profissionais dos Assistentes Sociais estavam voltadas para obtenção do consenso e controle da força de trabalho.

Assim, influenciados por teorias funcionalistas e positivistas, a intervenção profissional, pautada na individualização e psicologização das demandas por direitos, contribuiu para o obscurecimento das expressões da questão social, despolitizando as demandas dos usuários e direcionando-as para mudanças de ordem moral, visando a manutenção da ordem social capitalista.

As primeiras oposições políticas - ideológicas a esse cariz profissional, datam do Movimento de Reconceituação latino-americano. A recusa ao conservadorismo profissional, emerge nesse contexto, através da negação veemente do tradicionalismo profissional, levantando a bandeira do compromisso com a classe trabalhadora.

Com origem a partir do chamado cone sul (Chile, Argentina, Uruguai, Paraguai e Brasil), em 1965, o Movimento de Reconceituação é deflagrado com a proeminente participação de Assistentes Sociais, nas malhas das relações contraditórias entre a política (já em crise) e a modernização conservadora, desenvolvida no processo de industrialização dos anos 1950; as lutas sociais pela construção de uma alternativa de sociedade que 
superasse as desigualdades sociais e; as relações de dependência dos países latino-americanos com o imperialismo (LOPES, 1998).

Neste contexto, a questão do imperialismo era um dos eixos centrais explícitos nas lutas sociais, principalmente dos estudantes ou dos jovens profissionais recémegressos das universidades. No Serviço Social, segundo Lopes (1998), esta perspectiva estimulou uma rede de articulação em todo o continente incentivando a organização autônoma dos Assistentes Sociais em torno de dois grandes aspectos:

1) a crítica ao Serviço Social tradicional conservadore a função social exercida pela profissão no continente ( pautada na ética liberal burguesa); 2) possibilidade de superação daquele projeto profissional e de construção de um projeto alternativo de Serviço Social pautado na vinculação às lutas sociais por transformações radicais e a construção de uma alternativa de sociedade, baseada num sistema de controle social socialista (LOPES, 1998, p. 23).

O Movimento de Reconceituação desenvolveu-se marcado por divergências, correntes de pensamento diferentes e crises, seja de caráter antagônico entre as duas vertentes - modernização conservadora e construção de um projeto alternativo de sociedade -, seja no interior de cada uma dessas vertentes. No entanto, tais divergências, conforme a autora supracitada, mais que bloquear, impulsionaram a sua deflagração e expansão na perspectiva de construção de um novo projeto profissional.

Este movimento de efervescência política possibilitou a construção de uma proposta concreta de intervenção, definindo objeto e objetivos do Serviço Social para além do conservadorismo, através da aproximação com o marxismo, até então inexistente. Conforme Netto (2005, p. 145-146):

A reconceituação é sem qualquer duvida, parte integrante do processo de erosão do Serviço social 'tradicional' e, portanto, nesta medida, partilha de suas causalidades e características. Como tal, ela não pode ser pensada sem a referência ao quadro global (econômico-social, político, cultural e estritamente profissional) em que aquele se desenvolve. No entanto, ela se apresenta com nítidas 
peculiaridades, procedentes das particularidades latino-americanas; nas nossas latitudes, 'a ruptura com o serviço Social tradicional se inscreve na dinâmica de rompimento das amarras imperialistas, de luta pela libertação nacional e de transformação da estrutura capitalista excludente, concentrador' (FALEIROS, 1987, p. 51 apud NETTO, 2005, p. 146).

Conforme Netto (2005), o Movimento de Reconceituação latinoamericano era composto por basicamente dois segmentos: 0 primeiro apostava numa espécie de aggionarmento do Serviço Social capaz de modernizá-lo a ponto de torná-lo compatível com as demandas macrossocietárias, vinculando-se a projetos desenvolvimentistas de planejamento social. O segundo, por sua vez, era constituído por setores mais jovens e radicais, que intencionavam uma inteira ruptura com o passado profissional, de modo a sintonizar a profissão com os projetos de ultrapassagem das estruturas sociais de exploração e dominação.

A grande união do Movimento ver-se fraturada a partir de 1971, dividindo os seus protagonistas em dois grandes blocos: os reformistas democratas (desenvolvimentistas); e os radicaldemocratas - para os quais o desenvolvimento supunha a superação da exploração e dominação imperialista). Em meados da década de 1970, a renovação profissional materializada na Reconceituação foi interrompido pela repressão da ditadura militar na América Latina, tornando-se então, na opinião de Netto (2005), um movimento inconcluso e contido em sua história, principalmente a academia no tocante ao ensino, pesquisa e extensão. Entretanto, apesar da asfixia provocada pela ditadura nos países chaves da América Latina, Netto (2005) destaca que

[...] esta inconclusividade não fez do movimento algo
intransitivo, que não remeteria mais que a si mesmo.
Ao contrário, durante mais de dez anos, na sequencia
da década de 1970, a parte mais significativa do
espírito renovador da reconceituação, processado
criticamente, alimentou o que houve de mais
avançado no processo profissional latino-americano
(NETTO, 2005, p. 15).

A reconceituação latino-americana foi a herança base para a renovação crítica do Serviço Social brasileiro na década de 1980. 
Segundo Netto (2005) a passagem dos anos 70 aos 80, com a reativação do movimento operário-sindical e o protagonismo dos chamados novos sujeitos sociais, abriu novas perspectivas para os Assistentes sociais que pretendiam a ruptura com o tradicionalismo. "O que se operou foi uma retomada da crítica ao tradicionalismo a partir das conquistas da Reconceituação [...] comprometida com os interesses da classe trabalhadora, preocupada com a qualificação acadêmica e com a interlocução com as ciências sociais e investindo fortemente na pesquisa" (NETTO, 2005, p. 17).

Integrado ao sistema universitários em todos os níveis, o Serviço Social brasileiro assistiu ao desenvolvimento de uma perspectiva crítica, tanto teórica, quanto prática. Os desdobramentos desse processo vão resultar na construção de um novo Projeto ÉticoPolítico Profissional, vinculado a um projeto societário, propondo uma nova ordem social, voltado à equidade e a justiça social, numa perspectiva de universalização dos acessos aos bens e serviços relativos às políticas sociais. Neste contexto, a profissão busca o compromisso com a classe trabalhadora, através do aprimoramento intelectual, baseada na qualificação acadêmica e alicerçada na concepção teórico-metodológicas crítica e sólida.

O III Congresso Brasileiro de Assistentes Sociais, configura a materialização desse processo. Conhecido como Congresso da "Virada", ocorrido em 1979, constitui-se no mais importante marco histórico e político do Serviço Social brasileiro. Foi a partir deste, que a categoria, dinamizada pelas lutas da classe trabalhadora, ao enfrentar a hegemonia com o conservadorismo, iniciou a construção de um projeto profissional de ruptura com o conservadorismo da profissão. O referido congresso carrega as marcas dos avanços e conquistas sócio-profissionais.

Para Guerra 2009, o III Congresso Brasileiro de Assistentes Sociais pode ser interpretado como ato e como processo:

[...] Como ato encarna um momento em que significativos segmentos profissionais passam a enfrentar, aberta e pacificamente, o histórico conservadorismo da/na profissão, declarando a adoção de posicionamento ideo-político radical, constituindo uma vertente crítica da profissão, que 
passa a atuar na construção de uma nova direção social hegemônica. Como processo, o III CBAS é herdeiro do espírito critico [...] do Movimento de Reconceituação latino-americano, nutrido nas revoluções e lutas emancipatórias da América Latina e das diversas formas de enfrentamento do imperialismo norte-americano, e da ideologia do panamericanismo (GUERRA, 2009, p. 6).

Ainda conforme a autora supracitada, do ponto de vista da totalidade, a chamada Virada dos anos 1970, aponta determinações internas e externas ao Serviço Social. Em relação as determinações internas, é preciso considerar, que ela está articulada ao período da ditadura militar no Brasil e em outros países da America Latina e na luta contra o imperialismo norte-americano, pela libertação dos oprimidos e contra a histórica dependência e emancipação dos povos (GUERRA, 2009). Esse processo desnuda o papel do Estado que, enquanto Comitê Executivo da Burguesia, zela pelos interesses da classe dominante. Segundo Guerra (2009), tal desvelamento, permite que a profissão realize uma apreciação crítica da direção hegemônica da categoria, e da organização política representativa vigente à época, questionando sua funcionalidade aos interesses do capital. Nesse sentido, o enfrentamento aos sucessivos regimes ditatoriais, ao mesmo tempo em que impõe um refluxo dos movimentos de resistência, os potencializa.

No que concerne as determinações internas à profissão, Guerra (2009) afirma que a possibilidade da virada é resultado de um processo de acumulação de forças decisivas na sua construção. Aqui cabem destaques: ao processo de ampliação e laicização da categoria profissional, aprofundado no contexto da ditadura, o que permitiu a consolidação de um mercado de trabalho para os Assistentes Sociais; a inserção da profissão nos circuitos acadêmicos, com a criação da pós-graduação a partir de 1972 e, como fruto desse processo, uma produção teórica que questiona antigos paradigmas no que concerne ao Serviço Social como ramo do saber, a existência de objeto e métodos próprios, o endogenismo, a suposta neutralidade e assepsia dos conhecimentos/procedimentos técnicos e etc. A autora citada acima destaca ainda o protagonismo dos sujeitos profissionais em movimentos de resistência à ditadura, e a militância política que exercem, aproximando-se do marxismo (GUERRA, 2009). 
Nesse processo, de acordo com Netto (2003), o espírito crítico da formulação ${ }^{2}$ de Belo Horizonte $(\mathrm{BH})$, constitui-se na primeira formulação global de um Projeto profissional, que se irradia à outros contextos nacionais e latino-americanos. Tal formulação, procura romper com o tradicionalismo no plano teórico - metodológico, no plano da concepção e da intervenção profissional e no plano da formação (NETTO, 2003, p. 263). O espírito crítico da formulação de $\mathrm{BH}$ possa a fomentar debates e a constituir grupos de profissionais que, inseridos na discussão das ciências sociais à época, vão se tornando seus interlocutores qualificados.

A apropriação de um conhecimento que possibilita a crítica da sociedade burguesa de suas relações e sistemas institucionais, reconhecendo a necessidade de transformação, é característica central da constituição de uma vertente que se qualifica para operar uma análise mais próxima da realidade, identificando o momento mais oportuno para tal 'virada'. Ao mesmo tempo, a tradição de organização político-representativo da categoria, como legado da profissão, e a vinculação de suas lutas às mais gerais da sociedade, em sintonia com a reorganização do movimento operário e sindical e com os novos movimentos [...] que permite a renovação do Serviço Social (GUERRA, 2009, p. 8).

Assim, opera-se uma mudança no perfil profissional fazendo emergir uma nova geração de Assistente Sociais, cuja luta se expressa no movimento estudantil, e se alastra pelas entidades da categoria. O Encontro Nacional de Capacitação Continuada, promovido pelo Centro Latino Americano de Trabalho Social (CELATS), preparou, segundo lamamoto (2003, p. 108) "[...] a 'virada' política da luta contra o conservadorismo profissional". De acordo com a autora, o apoio financeiro e político das referidas entendidades latino-americanas na criação de uma base de organização sindical nacional, resultou na Associação Nacional de Assistentes Sociais e na Renovação Crítica do

2 O Método Belo Horizonte (BH) é considerado um marco na intenção de ruptura do Serviço Social brasileiro, no qual é possível identificar uma proposta profissional alternativa de intervenção as tradicionais práticas, apontando ao Serviço Social uma abordagem coletiva e mobilizadora, incentivando a organização social nas reivindicações das necessidades da classe trabalhadora. 
conjunto CFESS/CRESS, processo organizativo que esteve por detrás da virada do III CBAS.

O Serviço Social renovado é fruto de um conjunto de alterações na sociedade brasileira, e os Assistente Sociais fizeram parte dessas mudanças, sendo uma referência legitima para os movimentos sociais e sindicais e para as novas gerações. Nesse processo, ampliam-se os sindicatos e a categoria se aproxima de outras profissões, estabelecendo novos vínculos e alianças sociopolíticas.

A incorporação da perspectiva crítica, especialmente a de extração marxista, permitiu o salto quantitativo na análise de interpretação da sociedade burguesa, visando apreender suas contradições e romper com suas instituições. A constituição de uma massa crítica exige "[...] um esforço significativo da categoria no sentido de qualificar e formar em nível de graduação, adequando-a ao perfil profissional competente, crítico e compromissado, capaz de responder ao tempo histórico em curso" (GUERRA, 2009, p. 9).

Nesse sentido, os valores que até então norteavam a profissão passam a ser o eixo da polêmica profissional, e o questionamento de preconceitos e a afirmação de valores humanos emancipatórios, marcam a conquista do final dos anos 1980 e o inicio dos anos 1990. Os dilemas em termos de valores são superados com Código de Ética de 1986, e sua revisão e aprimoramento após a revisão de 1993, que coloca a profissão em sintonia com os valores emancipatórios, sintonizados com as lutas da classe trabalhadora, como veremos a seguir.

\section{OPROJETOÉTICO-POLÍTICO DOSERVIÇO SOCIALEM DEBATE: ENTRE A INTENÇÃO DE RUPTURAE O NEOCONSERVADORISMO}

Segundo Barroco (2009) os embates políticos mais expressivos entre os setores conservadores e a vertente de ruptura se expressaram nos momentos de reformulação do Código de Ética de 1986 e 1993. Progressivamente, de acordo com a autora citada, a práxis política e produção teórica passaram a desempenhar um papel fundamental na construção de um novo ethos crítico e democrático, voltado à ruptura com o irracionalismo do Serviço Social, o conservadorismo e o tradicionalismo. 
Nesse contexto, a reformulação do Código de Ética de 1986 assinalou a ruptura inédita da história profissional: o primeiro Código de Ética - desde a institucionalização do Serviço Social apoiado em teorias marxistas, explicitou seu compromisso com a classe trabalhadora, sujeito de sua intervenção.

No Código de Ética, em 1986, a ética profissional surgiu, pela primeira vez, como parte de um projeto, superando a perspectiva moral restrita aos sujeitos singulares. Porém a ética ainda não foi explicitada em sua natureza, do que decorreu a sua identificação com a política. Mas expressando uma mudança radical, a anterior subordinação da política à moral foi nele apresentada como uma subordinação da ética política. Estava, portanto, em curso a emergência de uma nova práxis política e que já tinha adquirido um sentido e uma substância bastante diversa daquela que anteriormente derivava da intenção singular dos indivíduos (BARROCO, 2009, p. 35).

Neste sentido, 1986 marca um momento de inflexão, que aponta para a superação que se processará na década de 1990, quando a dimensão ética e política se explicitam, adquirindo as condições para sua apreensão e exercício das duas especificidades.

Nos debates realizados para reformulação do Código de Ética de 1993, a dimensão ética da profissão foi analisada de forma inédita, propiciando o desenvolvimento de uma produção crítica apoiada em pensadores da filosofia e da teoria política, em novas referencias no campo do marxismo e nas fontes marxianas. Uma série de iniciativas práticas - voltada à capacitação, à mobilização, à reflexão e ao debate ético, em sua articulação com a política foram desencadeadas pelas entidades, revelando a compreensão da unidade entre essas dimensões do projeto profissional (BARROCO, 2009). Assim, a partir de 1993, o projeto de ruptura passou a ser tratado como Projeto Ético-Político, revelando a unidade entre ética e política.

Nas palavras de Netto (1999) o significado sócio histórico e ideopolítico do referido projeto

Tem em seu núcleo o reconhecimento da liberdade como valor central a liberdade concebida historicamente, como possibilidade de escolher 
entre alternativas concretas; daí um compromisso com a autonomia, a emancipação e a plena expansão dos indivíduos sociais. Consequentemente, o projeto profissional vincula-se a um projeto societário que propõe a construção de uma nova ordem social, sem dominação e/ou exploração de classe, etnia e gênero. A partir destas escolhas que o fundam, tal projeto afirma a defesa intransigente dos direitos humanos e a recusa do arbítrio e dos preconceitos, contemplando positivamente $\mathrm{o}$ pluralismo - tanto na sociedade como no exercício profissional (NETTO, 1999, p. 104-105).

Esse contexto demarca o espraiamento da perspectiva de intenção de ruptura para o conjunto da categoria dos assistentes sociais, atestando também a expansão da perspectiva teóricocrítica marxista entre a categoria e, a tentativa de superação dos limites ${ }^{3}$ do Movimento de Reconceituação. Em meados da década de 1980, essa perspectiva dá o tom da produção intelectual no Serviço Social e das reflexões acerca de uma formação e exercício profissionais comprometidos com as bandeiras de luta da classe trabalhadora (NETTO, 2005).

O Projeto Ético-político do Serviço Social ganha então maturidade na década de 1990, expressando-se através do Código de ética de 1993 e das novas Diretrizes Curriculares de 1996- ainda que não se tenha superado definitivamente o conservadorismo e determinados traços tradicionais na profissão - cuja direção aponta para uma formação social crítica e comprometida com os interesses da classe trabalhadora.

O aprimoramento intelectual é entendido nesse processo, como condição para apreender o real em sua concretude e

3 Netto (2005) destaca que este movimento foi permeado por equívocos e descaminhos: 1.A correta denuncia do conservadorismo conduziu muitas vezes, a um ativismo político que obscureceu as fronteiras entre a profissão e o militantismo - donde por vezes a hipostasia das dimensões político profissionais como um oficio heroico/messianismo; 2 . A recusa a teorias importadas resultou na valorização da produção "autóctone"; 3. O confusionismo ideológico acabou por engendrar a eclética mistura de teóricos. Paradoxalmente, a Reconceituação, abriu o dialogo do Serviço Social com a tradição marxista, recolheu desta quase sempre, o que nela havia de menos vivo e criativo. 
complexidade. Nesse processo, a interlocução com a tradição marxista e posteriormente com o pensamento marxiano forneceu as bases teórico-metodológicas para apreender a realidade sob a perspectiva de totalidade, que se constituiu na grande conquista desse projeto profissional, e ao mesmo tempo, no grande desafio colocado para a profissão.

A legitimidade e operacionalidade do Projeto Ético-político Profissional são demonstradas por Braz (2007) em três dimensões: A primeira de cunho jurídico-político da profissão, que compõe um conjunto de leis e resoluções abrangentes e ainda documentos e legislações legitimadas pela categoria, tais como o Código de Ética Profissional de 1993, a Lei de Regulamentação da Profissão (Lei 8.662/93) e as Diretrizes Curriculares para o Curso de Serviço Social de 1996. A segunda refere-se à dimensão político-organizativa da categoria, e a terceira, e por fim, referese a produção de conhecimento no Serviço Social.

O contexto socio-histórico e político em que o projeto ético-político amadurece e se afirma enquanto tal, configura, contrariamente a sua direção política-ideológica, o inicio da implementação do neoliberalismo no Brasil, que estabelece um período intenso de perda direitos, de privatizações do patrimônio público, seguido por desemprego massivo e do refluxo de muitos dos movimentos sindicais, que passam a enfrentar limitações estruturais para a sua organização política, como o desemprego e a terceirização.

A política de educação sofreu fortes ataques nesse processo, sobretudo a partir da gestão do então presidente da república Fernando Henrique Cardoso (1994-2002) com o sucateamento das instituições públicas de ensino fundamental, médio e superior. É nesse contexto que se expandem os cursos privados de Serviço Social, que na sua maioria não prezam por uma proposta de formação pautada no tripé ensino, pesquisa e extensão, o que prejudica-nosentido da autonomia-a elaboração de conhecimentos baseados numa análise crítica da sociedade, repercutindo no seio da categoria sob a forma de um neoconservadorismo profissional.

O exercício profissional dos assistentes sociais também é impactado, visto que as tendências das condições precarizadas de trabalho e as baixas remunerações, também atingem os 
profissionais, seja pelo contrato de trabalho instável ou mesmo "[...] por serem condicionados ainda por um lastro conservador em relação aos seus papéis e atribuições” (NETTO, 1996, p. 111).

Essa ofensiva do grande capital, também atinge as bases teóricoculturais, abalando fortemente as esquerdas mundiais. Assim, no exterior e no Brasil, intelectuais de monta aderem "[...] a marémontante da pós-modernidade (notadamente em sua versão neoconservadora)" (NETTO, 1996, p. 114). No início dos anos 1990, se registra no Serviço Social brasileiro a emergência da crítica formal às correntes marxistas no campo profissional “[...], a crítica, todavia, não se apresenta como antimarxista [...]” (NETTO, 1996, p. 114).

A pesquisa realizada por Santos (2007) identifica no Serviço Social a incorporação da pós-modernidade, não somente por autores do campo conservador - históricos opositores da vertente de ruptura - mas também no campo marxista, cuja apropriação do marxismo, segundo a autora, é atualmente epistemológica. Nos dois grupos a retórica pós-moderna atua como um elemento (re)atualizador de traços arcaicos da profissão: os referentes ao conservadorismo profissional e a instrumentalização das investidas deslegitimadoras "[...] da direção social estratégica fundada na razão dialética” (SANTOS, 2007, p. 14).

É importante destacar, que o perfil das polêmicas pós-modernas no terreno do Serviço Social, adensam o combate travado contra a teoria social marxiana. Dessa forma, uma característica constante das teorias pós-modernas, é a simplificação da tradição críticadialética, visando demonstrar a sua insuficiência na atualidade. Os desdobramentos disso, segundo Santos (2007), são as críticas a totalidade como totalitarismo; à ortodoxia como dogmatismo e; à universalidade como estruturalismo.

No Serviço Social, a apropriação do pensamento pós-moderno, aponta para diferentes características. De um lado, tem-se “[...] aquelas críticas de origem conservadora que rejeitam o marxismo e atualizam-se absorvendo, numa moldura sincrética, as proposições pós-modernas" (SANTOS, 2007, p. 87). Neste, a autora supracitada, identifica tendências que para além de investir contra a legitimação da direção teórico-metodológica, investe principalmente na deslegitimação da direção ético-política, consolidada em oposição 
ao conservadorismo. Por outro lado, assiste-se a existência daquelas críticas que, "[...] ainda reivindicando o marxismo em alguns dos seus aspectos, recomendam a superação de 'lacunas' e o aumento de sua potencialidade aplicativa com os 'paradigmas pós-modernos"' (SANTOS, 2007, p. 87).

Em meio a conjuntura de avanços e retrocessos no que tange às conquistas da classe trabalhadora, a eleição presidencial ocorrida em 2002 configurou um novo marco político no Brasil: a vitória esmagadora de um partido político de esquerda que, pela primeira vez na história do país, elegeu um representante da classe trabalhadora. Esta guinada representou para os movimentos sociais de esquerda - que apesar das adversidades não deixou de alimentar (nos termos de Gramsci) o otimismo da vontade - a expectativa de mudanças no que se refere à ruptura com a política neoliberal, que foi implementada a partir do governo Collor e aprofundada no governo de FHC. Grandes foram as expectativas depositadas na vitória eleitoral de Lula, entretanto, como sinaliza Braz (2004):

Se a eleição de Lula significou impor uma relativa inflexão ao projeto neoliberal, imprimindo tensionamentos de natureza distinta ao quadro político nacional, na medida em que forças políticas oriundas 'de baixo' se credenciaram a assumir espaços antes nunca possíveis a ela, por outro, o projeto vitorioso esbarra na hegemonia mundial do neoliberalismo, que suplanta politicamente projetos nacionais, Estados nacionais, suas instituições e formas de representação política (BRAZ, 2004, p. 52).

Dessa forma, o governo Lula manteve os mesmos elementos de contrarreforma ${ }^{4}$ vinculados aos programas de ajuste macroeconômico da era FHC, evidenciando a face do Estado neoliberal. As políticas implementadas durante sua gestão, seguiram as diretrizes do Estado máximo para o capital, caminhando

4 Termo utilizado por Behring (2008) para se referir ao aspecto regressivo das reformas feitas no Estado brasileiro a partir do governo de Fernando Collor de Melo até os dias atuais. Bering assinala tal aspecto, considerando os impostos regressivos e destrutivos e a obstacularização da agenda radicalmente progressiva e democrática demarcada pelos movimentos sociais e dos trabalhadores. Tem-se, portanto, a implementação de um conjunto de reformas orientadas para o mercado e uma adaptação passiva às novas configurações do capitalismo contemporâneo. 
na contramão de um novo Projeto Societário, contrário a sociabilidade do capital. Nesse contexto, presencia-se a ampliação e aprofundamento da mercantilização da universidade pública e os mecanismos de precarização da qualidade do ensino superior, desprezando o tripé ensino-pesquisa-extensão, defendido pelas Diretrizes Curriculares do Curso de Serviço Social de 1996, colocando em risco o perfil profissional preconizado nas mesmas.

O perfil profissional defendido nas referidas diretrizes curriculares, passam a sofrer maiores ameaças com a expansão desenfreada dos Cursos de Graduação em Serviço Social à distância. Os dados da pesquisa realizada por lamamoto (2009), revelam que a tendência é de consolidação de um campo majoritário de Assistentes Sociais de formação profissional precarizada, o que coloca a possibilidade, de num futuro próximo, as entidades da categoria profissional possam vir a ser ocupadas por representações balizadas num Projeto Profissional com uma direção social e política contrárias ao Projeto vigente.

Segundo dados do Instituto Nacional de Estudos e Pesquisas Educacionais Anísio Teixeira (INEP) do Ministério da Educação (MEC) em março de 2007, o país tinha 253 cursos de graduação em Serviço Social (incluindo os cursos presencias e à distância). Destes, eram levados a efeitos por instituições públicas, responsáveis por 5358 vagas (16\%) e 207 oferecidos por instituições privadas de ensino superior com 27465 vagas (84\%). O conjunto do ensino superior na área totalizava 32.823 assistentes sociais em formação no país, próximo da metade do contingente profissional atual (IAMAMOTO, 2009, p. 39).

Diante disso, é possível afirmar que as novas determinações, típicas da dinâmica societária do capitalismo, tem implicado no resgate (de forma travestida) de traços conservadores da profissão acrescidos de novos elementos, tensionando as possibilidades de efetivação do Projeto Ético-político, ao mesmo tempo em que apontam os desafios à materialização deste.

O projeto profissional ora vigente, embora tenha uma direção hegemônica construída historicamente, como a realidade tem demonstrado, não é um corpo homogêneo, e distintas opções 
políticas e teórico - metodológica têm ganhado espaços e adesão de Assistentes Sociais. Concepções conflituosas acerca do significado social da profissão, da dimensão ético-política, das atribuições profissionais, da análise das expressões da questão social, do trabalho em equipes interdisciplinares entre outros, tensionam o Projeto Profissional hegemônico. Tal afirmação torna-se evidente ao nos depararmos, por exemplo, com o movimento na categoria, denominado por seus seguidores de Serviço Social clínico. Este, configurado por um grupo heterogêneo de Assistentes Sociais especializados em diferentes abordagens clínicas ou terapêuticas, reivindicam o reconhecimento da intervenção profissional terapêutica por parte das entidades da categoria como atribuição dos Assistentes Sociais.

Na contramão da direção crítica apontada pelo Projeto Profissional hegemônico, Faleiros (2003) aponta pensar:

[...] que na prática do Serviço Social seja possível o exercício da terapia e da clínica não só em articulação com a política, mas como uma política de fortalecimento do usuário no exercício de seus direitos, uma alternativa de orientação social, como prevê a Lei de Regulamentação da Profissão. [...] Na relação terapêutica de empoderamento sai fortalecida a decisão do usuário, que vai estabelecer, na comunicação, o desenvolvimento do seu processo de saída das crises, de alívio de tensões e sofrimentos, de uso de recursos sociais e jurídicos [...] (FALEIROS, 2003, p. 33).

Marilda lamamoto (2008), alerta sobre forte conotação liberal contida na noção de empowerment, pois, centrada no interesse do individuo nas lutas pelos interesses civis, trata-se certamente de "[...] uma noção teórica estranha a teoria social crítica e ao método que lhe é inerente, ainda que, para Faleiros, o esforço de sua resignificação se coadune com a inspiração gramsciana, que ele registra como marca de sua obra" (IAMAMOTO, 2008, p. 301).

Ressalta-se que no debate sobre o empoderamento predomina uma prática profissional psicologizante expressa na polêmica das abordagens clínicas e terapêuticas, do retorno a uma concepção conservadora e moralista dos direitos sociais. As 
abordagens clínicas e terapêuticas, para além de retomar traços conservadores vinculados ao serviço social de casos, tem claros aportes nos discursos calcados no chamado "[...] pensamento pós-moderno de análise dos fenômenos microssociais neles mesmos, da supervalorização do efêmero, molecular, descontínuo e fragmentado" (SOUSA, 2005, p. 72-73).

Entre outros elementos, as vertentes neoconservadoras da prática profissional, contribuem para a polêmica sobre a existência de uma crise no Projeto ético-político formulado na década de 1980. Nesse embate conjuntural, Braz (2007) adensa a reflexão sobre a chamada "crise" do Projeto ético-político profissional, afirmando que há dois problemas centrais, que articulados, tendem a dissolver a hegemonia conquistada: O primeiro, referese a "[...] ausência de uma proposta alternativa à do capital na sociedade brasileira, capaz de unificar interesses sociais distintos relativos ao trabalho" (BRAZ, 2007, p. 6). Segundo Braz (2007, p. 7) a crise de projeto societário da classe trabalhadora - devido ao neoliberalismo catalisado pelo governo Lula, o que provocou uma crise nos partidos de esquerda - impõe uma crise para o projeto profissional, visto que até o momento não se conseguiu unificar forças políticas capaz de conduzir o ascenso das massas.

O segundo problema apontado por Braz (2007), diz respeito as condições contemporâneas que atacam a formação e o exercício profissionais do Assistente Social no Brasil. Aqui o crescimento desenfreado da mercantilização do ensino superior, e a sua expansão na modalidade à distância (público e privado), são os principais argumentos utilizados pelo autor para demonstrar, que na contemporaneidade, a hegemonia do projeto profissional encontra-se em crise.

Refletindo sobre os rebatimentos de tal conjuntura no Serviço Social, Braz (2007) constata que há uma voraz massificação e desqualificação da formação profissional, o que repercutirá futuramente no exercício da profissão, posto que haverá um perfil profissional radicalmente oposto ao proposto pelas Diretrizes Curriculares da ABEPSS. Tal quadro tende, ainda, a dificultar a formação de novos quadros teóricos-políticos, isto é, aqueles que tenham de fato vivenciado a universidade, tanto no âmbito 
da solidez teórica, quanto no da experiência política junto aos movimentos sociais (partidário, sindical, popular, estudantil, dentre outros). Tomando por base a análise do quadro em tela: “Aqui o projeto profissional corre sério risco. Outras expressões políticas da profissão de variados tons neoconservadores mais ou menos organizadas podem ganhar espaço e terreno em meio à degradação das condições de trabalho profissional" (BRAZ, 2007, p. 7-8).

Netto (2007) também refletindo sobre a chamada crise do Projeto Profissional corrobora os apontamentos de Braz (2007), apontando dois níveis no qual se verifica o que ele denomina de "Processo de Inviabilização do Projeto Ético Político". O primeiro nível, diz respeito a minimização dos objetivos e funções profissionais dos assistentes sociais, isto devido a centralização destes na política de assistência social, o que reduz o escopo de atuação do Serviço Social. Para o autor, esta redução só tem se efetivado porque tem sólidos amparos em determinados vetores da categoria profissional que a entendem ainda restrita à assistência social.

Por sua vez, o segundo nível da chamada inviabilização do Projeto Ético-político, refere-se aos requisitos (teórico, práticos e institucionais) para o seu exercício. Aqui, o autor destaca o debate sobre os elementos contemporâneos de sucateamento do ensino superior, via expansão do ensino privado e/ou proliferação das modalidades de ensino à distância, que incidi na precarização da formação profissional dos Assistentes Sociais, já tratados por Braz (2007).

Contestando, os argumentos de Netto e Braz, Sâmia Ramos (2009) chama a atenção para o fato de que o Projeto Profissional jamais esteve em sintonia com a direção social da política brasileira, visto que o mesmo amadureceu e consolidou-se, desde sempre, em contexto histórico adverso a sociedade do capital.

Como se sabe, o capitalismo contemporâneo tem atuado de forma destrutiva, no entanto, de acordo com pensamento da autora, é preciso que a categoria utilize sua capacidade de mobilização "[...] para produzir, conjuntamente com outros sujeitos individuais e coletivos, estratégias com potencial para enfrentar este processo, para que possamos manter a hegemonia do projeto profissional" (RAMOS, 2009, p. 45). 
Cabe sinalizar que, essa é a luta que segmentos importantes da categoria têm travado nas últimas três décadas, principalmente nos anos 1990, com a implementação do neoliberalismo no governo Collor, momento expressamente desfavorável às conquistas da classe trabalhadora e a materialização do Projeto ético-político, tal como se apresenta, de forma intensificada, as dificuldades para a referida classe, na conjuntura do governo petista.

[...] A profissão; o projeto ético político profissional e o conjunto da vida social sofrem as repercussões das investidas do capital para garantir seus projeto de acumulação, bem como as dificuldades de elaborar um projeto anticapitalista de esquerda [...]. Acredito que não temos, na conjuntura atual, elementos concretos para concluir que existe uma crise de hegemonia do projeto ético-político do Serviço Social, pois nas suas três esferas constitutivas não há indicativos para tal [...]. Do ponto de vista da produção do conhecimento, notamos que a predominância da teoria social crítica em nossas produções permanece [...]. No âmbito dos nossos instrumentos normativos [...] não aconteceram, nos marcos legais, [...] mudanças regressivas. [...]. E, na dimensão da organização política, penso, também, que mantemos, na multiplicidade das entendidades representativas nacionais, [...] uma direção política de sustentação ao projeto profissional hegemônico(RAMOS, 2009, p.47).

Assim, apesar do contexto adverso, é preciso considerar que o Serviço Social prosseguiu no campo de resistência teóricopolítico, onde o Projeto ético-político se inclui. É na trincheira da resistência e do enfrentamento à desigualdade social que as entendidades nacionais da categoria e assistentes sociais de diversas localidades do país assumiram explicitamente seu compromisso com Projeto Profissional.

Para Ramos (2009), a pluralidade legitimada pela categoria profissional, expressa por meio das lutas, divergências, discussões, confronto de ideias e polêmicas teóricas-políticas, demonstram que um projeto que conquista hegemonia não será exclusivo, visto que determinados segmentos podem propor outros projetos divergentes do hegemônico, quando analisam a sociedade e a profissão sob outros fundamentos e possuem, 
inclusive, concepção, forma e métodos diferentes de fazer a política. A hegemonia, como direção ética-política e teórica, sustenta uma determinada direção estratégica, representando uma dada compreensão de realidade, de profissão e de formas de enfrentamento adotadas pelos segmentos de Assistentes Sociais e suas entidades representativas, ainda que não seja majoritária na categoria profissional, pois "[...] a hegemonia não se representa meramente pela quantidade" (RAMOS, 2009, p. 43).

O entendimento da hegemonia articulada ao pluralismo enquanto direção social, expressa o predomínio de uma direção política construída por meio de uma vontade coletiva, democrática, não coercitiva e que pressupõe a não eliminação ou repressão de interesses contraditórios a direção social predominante.

Assim, como qualquer Projeto Profissional, o Projeto éticopolítico do Serviço Social, também é marcado por divergências e disputas, isto é, a direção intelectual e ética de base marxiana, defendida pelas entidades organizativas da categorias e por segmentos profissionais importantes, não garantem por si uma prática política contestadora. Além do mais, é preciso considerar, conforme destaca lamamoto (2008) as tensões inerentes à relação entre projeto profissional - que afirma o assistente social como um ser prático-social dotado de liberdade e teleologia, capaz de realizar projeções e buscar implementá-las na vida social - e a condição do Assistente Social, enquanto trabalhador assalariado. Nessas condições, a autonomia do trabalho profissional encontra limites, posto que, na condição de assalariado, os Assistentes Sociais, assim como os demais trabalhadores, estão submetidos ao processo de mercantilização que "[...] subordina o trabalhador aos ditames do trabalho abstrato, impregnando-o dos dilemas da alienação, impondo condicionantes socialmente objetivos à autonomia do Assistente Social na condução do seu trabalho e na integral implementação do projeto profissional" (IAMAMOTO, 2008, p. 37). Desta forma, “[...] não há uma identidade imediata entre a intencionalidade do projeto profissional e os resultados derivados da sua efetivação" (IAMAMOTO, 2008, p. 37).

Se de imediato, esse é um dos limites prático-operativo para materialização do Projeto ético-político, Mota (2010), chama 
atenção para o fato de que na experiência cotidiana, pela via da formação político-profissional, o sujeito Assistente Social tem a possibilidade de enriquecer suas objetivações, acionar práticas político organizativas de resistências e lutas, que tenham impactos transformadores nos processos reais onde se realiza o seu cotidiano.

Nas palavras da autora:

As resistências são tênues, porém reais, a prática político organizativa é essencial, posto que deve estabelecer o elo entre a formação profissional e formação política da categoria profissional como forma e meio de captar as reais demandas concernentes ao projeto profissional, assumindo a sua direção de dirigente no 'trânsito' do momento econômico -corporativo para o momento éticopolítico (MOTA, 2010, p. 54).

Destarte, a categoria tem procurado resistir, mobilizando os meios possíveis para não sucumbir ao esvaziamento da dimensão política profissional construída de forma histórica e única na história do Serviço Social em todo o mundo. Caminhando na contramão do neoliberalismo, temos assistido ao surgimento e fortalecimento de lutas expressivas de movimentos sociais em todas as regiões brasileiras, com forte participação de segmentos dos Assistentes Sociais, que tem remado contra a maré das contrarreformas capitalistas. As respostas do Estado têm sido um forte processo de criminalização, a exemplo das prisões arbitrárias de militantes de movimentos sociais a que temos assistido nos dias de ontem e hoje.

Como defendido por Ramos (2009), a produção crítica nas produções do Serviço Social permanece hegemônica, e assim, o serviço social brasileiro tem assumido a posição de referência teórica no âmbito da teoria social crítica, sendo utilizado por diversas áreas que buscam fazer interlocução com o marxismo. Além disso, no que concerne dimensão político organizativa, evidencia-se o protagonismo político e compromisso do conjunto CFESS/CRESS e da ABEPSS a teoria social crítica, ou seja, apesar da existência de setores conservadores é possível afirmar que ainda não há crise de hegemonia do Projeto Profissional. O contexto sócio-histórico, político e econômico são desafiadores, no entanto, 
é preciso que tenhamos, como afirma Cisne (2008, p. 36), “[...] a histórica paciência revolucionária mediada pela maturidade política [...]". E ainda, o dever político de dizer que a história não acabou "[...] afirmando em ações e palavras não apenas a viabilidade, como a necessidade de continuarmos na luta por um novo mundo. Destarte, enquanto houver sujeitos, a história permanecerá encharcada de possibilidades" (CISNE, 2008, p. 36).

\section{CONSIDERAÇÕES FINAIS}

A luta entre distintos projetos societários estão na ordem do dia, tendo em vista o avanço do conservadorismo na contemporaneidade e as agressivas investidas do capital contra os interesses da classe trabalhadora. Nesse confronto, é perceptível o debate do pensamento pós moderno com suas diversas estratégias que visam corroer ideologicamente os fundamentos emancipatórios, a noção de totalidade e o entendimento de que a história é uma construção dos homens, e esses homens ao compreender sua essência histórica tem o poder de transforma-la (MARX, 1980).

As condições objetivas desse processo fogem às mãos e à intencionalidade dos Assistentes Sociais que defendem o Projeto crítico/ hegemônico dessa profissão. Entretanto, quanto ao direcionamento, o Serviço Social conta com um acervo de produções que em sua direção ética e política é capaz de orientar estratégias no sentido do seu rumo ético e de sua medida política (BARROCO, 2009).

Nesse sentido, é visível que a categoria continua a investir nos espaços de representação, seja nos movimentos sociais, conselhos de direitos de políticas setoriais, seja através de fóruns e/ou militâncias em partidos de "esquerda". Sabe-se que são experiências em processo, mas que tem potencial para arregimentar forças populares visando construir uma agenda política mais abrangente, com uma finalidade anticapitalista, ou ainda conforme Netto (2007), apostando “[...] nas contradições que emergem desse processo determinado pelas lutas de classe, e que alimentam as estratégias e o potencial do enfrentamento, através da nossa ação política organizada" (NETTO, 2007 apud RAMOS, 2009, p. 46).

No que concerne aos momentos de avanço e retrocesso do conservadorismo na profissão,e as vertentes que daí emergem, conside- 
ra-se que o contexto capitalista contemporâneo, é extremamente propício ao avanço dessas expressões neoconservadoras, principalmente porque, no bojo das recentes contrarreformas do ensino superior implementadas pelo governo Lula, dentre as profissões que tiveram seu processo formativo desqualificado está o Serviço Social.

Assim, que a categoria se debruce sobre a análise desses processos, visando o enfrentamento das expressões neoconservadoras no Serviço Social contemporâneo. Destaca-se que, são parcos os estudos referentes ao tema. Se a categoria deseja manter a direção crítica do projeto hegemônico, faz-se necessário realizar estudos e pesquisas propositivas para tal conjuntura, pois se o projeto profissional não se encontra em crise, o aprofundamento e consolidação de vertentes conservadoras podem ganhar mais espaços para consolidação de um projeto regressivo à profissão - sobretudo em função da ampliação do número de profissionais formados em condições precárias e encharcados por teorias pósmodernistas que inviabilizam o entendimento da direção social crítica dada ao Projeto hegemônico. Tais profissionais, tendo em vista a precariedade da sua formação, por vezes, não se sentem representados pelo conjunto CFESS/CRESS, principalmente no que concerne as lutas que segmentos da categoria tem travado contra a educação à distância, e a defesa das normativas que - bem regulam a formação e o exercício profissional.

Como bem destaca Ramos (2009), um projeto pressupõe a presença, nos indivíduos, de um valor ético fundamental. E esta precisa ser lapidada cotidianamente. Em se tratando de projetos profissionais, a sua construção se consolida nos fóruns de discussão e deliberação; espaços que garantam a participação democrática de diferentes inserções geográficas, áreas de atuação e concepções ideológicas e teóricas. Concordando mais uma vez com Ramos (2009, p. 47), “[...] os sujeitos profissionais precisam se encontrar; é pois a presença que tem a força de mobilizar e de promover iniciativas que favoreçam a apreensão da realidade, instigando-nos para irmos além do lugar em que estamos, pois ter projetos é entrar em movimento, é romper estagnações".

A materialização do Projeto Profissional exige o estabelecimento de laços cada vez mais estreitos. Mas para isso caberá ampliarmos, nos 
diferentes espaços sócio-ocupacionais de inserção dos assistentes sociais, a articulação com a própria categoria, com os movimentos sociais, na medida em que os sujeitos coletivos revolucionários necessitam se emancipar politicamente - reconhecendo os limites desta emancipação nos marcos da ordem gerida pelo capital para alcançarmos a emancipação humana.

\section{REFERENCIAS}

BRAZ, Marcelo. A hegemonia em xeque. Projeto ético-político do Serviço Social e seus elementos constitutivos. Revista Inscrita, Brasília (DF), ano 7, n. 10, 2007.

BRAZ, Marcelo. O governo Lula e o projeto ético-político do Serviço Social. Serviço Social \& Sociedade, São Paulo, n. 78, 2004.

BARROCO, Lúcia. Ética e política entre a ruptura e o conservadorismo. Revista Inscrita, Brasília (DF), ano 9, n. 12, 2009. BEHRING, Elaine. Brasil em contra-reforma, desestruturação do Estado e perda de direitos. São Paulo: Cortez, 2008.

CISNE, Mirla. Resistência de Classe no Brasil Contemporâneo: mediações políticas para o enraizamento do Projeto do Projeto Ético-político do Serviço Social. Temporalis, Brasília (DF), ano 8, n. 16, 2008.

FALEIROS, Vicente de Paula. Mesa Redonda: O Serviço Social Clínico e os desafios ético-políticos postos ao Serviço Social. Revista Em foco, Rio de Janeiro, 2003.

GUERRA, Yolanda. A virada do Serviço Social. Revista Inscrita, Brasília (DF), ano 11, n. 12, 2009.

IAMAMOTO, Marilda. O Serviço Social na cena contemporânea. In: CFESS; ABEPSS. Serviço Social: direitos sociais e competências profissionais. Brasília (DF): CEAD; UnB, 2009.

IMAMOTO, Marilda. Serviço Social em tempos de Capital Fetiche: capital financeiro, trabalho e questão social. 2. ed. São Paulo: Cortez, 2008.

IMAMOTO, Marilda. O Serviço Social na contemporaneidade: trabalho e formação profissional. São Paulo: Cortez, 2003. 
LOPES, Josefa Batista. O Serviço Social na America Latina: nas malhas da modernização conservadora e do projeto alternativo de sociedade. Tese (Doutorado em Serviço Social)-Pontíficia Universidade Católica de São Paulo, São Paulo, 1998.

MARX, Karl. O Capital: crítica da economia política. Livro I, Volume 2. Rio de Janeiro: Civilização Brasileira, 1980.

MOTA, Ana Elizabeth. Projeto Profissional e Projeto Societário. Revista Inscrita, Brasília (DF), ano 11, n. 12, 2010.

NETTO, José Paulo. Das ameaças a crise. Revista Inscrita, Brasília (DF), ano 7, n. 10, 2007.

NETTO, José Paulo. O Movimento de Reconceituação 40 anos depois. Serviço Social \& Sociedade, São Paulo, n. 84, 2005.

NETTO, José Paulo. Ditadura e Serviço Social: uma análise do Serviço Social no Brasil pós-64. São Paulo: Cortez, 2003.

NETTO, José Paulo. A construção do projeto ético político do Serviço Social frente a crise contemporânea. In: CAPACITAÇÃO em Serviço Social e política social. Brasília (DF): CFESS; ABEPSS; CEAD; UNB, 1999.

NETTO, José Paulo. Transformações Societárias e Serviço Social notas para uma análise prospectiva da profissão no Brasil. Serviço Social \& Sociedade, São Paulo, n. 50, 1996.

NETTO, José Paulo. Capitalismo Monopolista e Serviço Social. São Paulo: Cortez, 1992.

RAMOS, Sâmia. Limites e Possibilidades históricas do Projeto Ético Político. Revista Inscrita, Brasília (DF), ano 11, n. 12, 2009.

SANTOS, Josiane S. Neoconservadorismo pós-moderno e Serviço Social brasileiro. São Paulo: Cortez, 2007.

SOUSA, Adrianyce A. S. Pós-modernidade: fim da modernidade ou mistificação da realidade contemporânea? Temporalis, Brasília (DF), ano 5, n. 10, 2005. 